\title{
Plan de Marketing en la PYME
}

\author{
Marketing plan in the SME \\ María Dolores Martínez García ${ }^{a}$, Ximena Márquez Hernández ${ }^{b}$
}

\begin{abstract}
:
The Marketing Plan is not exclusive of big enterprises, the author about people in marketing plan allow guide small and medium enterprises as a necessary tool in order to tracing organizational objectives retaking the elements that integrate the develop of plan that allow optimization of resources and reduce of prevential problems facilitate the situational diagnostic analysis.
\end{abstract}

Keywords:

Planning, Marketing, SME's

Resumen:

Un plan de mercadotecnia no es exclusivo de las grandes empresas, el autor acerca a las personas la planeación de mercadotecnia que permite orientar a la pequeña y mediana empresa como herramienta necesaria para el seguimiento de los objetivos organizacionales, retomando los elementos que integran el desarrollo de un plan que facilite la optimización de recursos y la reducción de problemas prevenibles mediante un análisis de diagnóstico situacional.

Palabras Clave:

Planeación, Mercadotecnia, Pyme

\section{Introducción}

El plan de marketing en la PYME es un libro publicado en marzo de 2013 en una tercera reimpresión con 228 páginas y 6 capítulos el autor desglosa los elementos necesarios para generar un plan de marketing en una PYME.

\section{Desarrollo}

En el capítulo uno el autor explica que los empresarios se encuentran en un entorno de retroalimentación continua por lo tanto es común la utilización del término mercadotecnia en sus estrategias, este concepto se encuentra directamente relacionado con el consumidor, el usuario o el cliente para el que se desarrollan los productos o servicios orientados a la satisfacción de necesidades, contar con un marketing enfocado beneficia a la organización, entre más encaminadas son las estrategias permite la alineación de la planeación, determina el éxito y diferenciación ante los competidores para conseguir fidelización.

El responsable de mercadotecnia debe superar la mentalidad tradicional de producción que contrasta con el enfoque de marketing, definir esta diferenciación evitara conflictos internos entre los responsables de las áreas al tener objetivos congruentes que permitan concretar una autentica visión alternativa del marketing en la empresa, los mercados actuales son cada vez más exigentes e informados, es necesario actuar en función de las tendencias definidas por los clientes, detectando segmentos y nichos en crecimiento, descubriendo la necesidad de ampliar la oferta de los productos, generando ventajas competitivas de la empresa para diseñar una estrategia de mercadotecnia adecuada.

a Autor de Correspondencia, Universidad Autónoma del Estado de Hidalgo, Instituto de Ciencias Económico Administrativas, Área Académica de Administración, ORCID:0000-0002-3606-8010,Email: maria_martinez1078@uaeh.edu.mx 
El marketing tiene dos inclinaciones, por una parte, se encuentra el marketing estratégico que se enfoca desde el mediano a largo plazo anticipándose al mercado y a las necesidades en constante cambio, en otra vertiente el marketing operativo se ejecuta en plazos cortos para situaciones no previstas con anterioridad, o bien que cambiaron respecto a lo que se consideró previamente.

Por ello para lograr los objetivos previstos es necesario diferenciar el marketing transaccional encaminado en una venta direccionando a la organización al marketing relacional que se dirige a la fidelización, los costos de atraer a un nuevo cliente superan al de mantener a un cliente satisfecho.

Cuando una empresa tiene definida su visión hacia sus consumidores no debe perder de vista a los clientes con los que tiene contacto constante y pueden aportar mejoras e ideas innovadoras a lo que se le conoce como marketing interno, los empleados son los primeros clientes que tiene una empresa, quienes reflejaran su satisfacción, motivación y compromiso en el servicio al cliente, las empresas precisan adaptarse al entorno, las tecnologías están en constante actualización, las fronteras se encuentran menos divididas, los consumidores también evolucionan en cuanto a sus necesidades, expectativas y parámetros de satisfacción, cuando una organización considera todos estos elementos en sus tácticas puede convertirse en un referente de su sector.

Planificar es el reto de decidir en la actualidad las acciones que se ejecutaran posteriormente con el conocimiento existente, así lo explica el autor en el capítulo dos, siendo una actividad de análisis y reflexión a nivel interno y externo de la empresa, planificar previene ser una organización sin estrategia considerando la posibilidad de cambios y la limitada precisión hacia eventualidades poco comunes, orientándose al cumplimiento de objetivos como prioridad, logrando una capacidad de respuesta rápida a situaciones no previstas, un buen plan es flexible al adaptarse a los contextos mediante un proceso sistemático de mercadotecnia, la rentabilidad está ligada a una correcta ejecución de una planeación en todas las áreas de la empresa uniendo la previsión estratégica a los objetivos de mercadotecnia.

Un plan de mercadotecnia es un documento escrito sistematizado y estructurado donde se definen tanto funciones como responsabilidades que facilita el control de su ejecución, sirve para alcanzar los objetivos organizacionales, desarrollar equipos integrales con compromisos en común al ser elaborado por un equipo de personas expertas en sus áreas y no solo por el responsable de marketing, los puestos de trabajo relacionados con el plan en grandes organizaciones son; Director comercial, director de marketing, jefe de ventas nacional e internacional además del key account manager, estas actividades en una PYME pueden recaer en una persona que las desempeñe pero no limita la posibilidad de planificar una estructura de personal con orientación de marketing a mediano o largo plazo.

La elaboración de un plan estratégico se genera después de detectar un diagnostico situacional que permite la definición de objetivos en conjunto con las tácticas para alcanzarlos, requiere un análisis integral de las situaciones internas y externas que son plasmadas en una matriz de dirección de crecimiento, permitiendo realizar profundización en las opciones estratégicas de crecimiento, empleando los criterios generales para la priorización de mercados productos o segmentos a través de planes de acción para definir estrategias funcionales que combinen los medios al alcance de la organización con apoyo del mix de marketing, la descripción detallada la plantea el autor en al capítulo tres.

Los planes que se desarrollan en una organización requieren seguimiento, es la propuesta que hace el autor en al capítulo cuatro, también es necesario definir parámetros de control que comparen el resultado y desempeño de los objetivos fijados, analizando las variaciones entre las metas establecidas, detectando las desviaciones en caso de que se presenten, corrigiendo las acciones que desvíen el logro de los objetivos para lo que se desarrolla el modelo de indicadores, en la cultura corporativa es necesario mantener una mentalidad de marketing reconociendo la necesidad de apoyarse en consultorías cuando sea necesario, detectando la viabilidad de lo planeado una vez que este se aprueba el paso subsecuente es la ejecución del plan.

El autor explica en el capítulo cinco la forma de trabajo de SDV consultores, una empresa de consultoría que apoya en la generación de un plan de marketing, para una PYME muchas veces el contratar una consultoría no está en sus posibilidades de rentabilidad a corto plazo pero algunas veces cuando se tiene el recurso necesario no se tiene un panorama previo de como contratar o seleccionar a la empresa consultora, en el capítulo se desarrolla un plan de mercadotecnia a través de SDV Consultores, con todos los elementos mencionados en el capítulo anterior que brindan a los empresarios un panorama de las actividades que desarrolla un equipo de profesionales expertos cuando se le contrata.

Un plan de mercadotecnia industrial no presenta características que lo excluyan de un plan para otro sector, es la propuesta que hace el autor en el capítulo seis, sin embargo, es importante considerar los elementos específicos del sector para la toma de decisiones, los 
resultados de un plan de marketing son medibles y permiten tomar decisiones

El autor concluye con un epilogo hacia una cultura corporativa donde invita a los empresarios a no incurrir en los errores pasados cometidos por otras organizaciones, con los pilares básicos de pensamiento estratégico permitiendo una visión global e internacional, redefiniendo el termino innovación e impulsando a la organización a una cultura corporativa.

\section{Conclusiones}

El libro toma elementos del plan de marketing enfocados a organizaciones de gran tamaño aterrizando los conceptos para la aplicación en pequeñas y medianas empresas, así como para empresas de diferentes sectores ampliando la aceptabilidad por parte de las empresas, las dudas frecuentes de un plan de mercadotecnia se pueden resolver mediante la lectura del libro, el autor destaca la necesidad de la mentalidad de marketing por parte de los directivos para poder desarrollar un plan congruente con los objetivos organizacionales, considerando un diagnostico situacional realista con un seguimiento necesario para el cumplimiento o modificación de lo previsto, el autor explica que el tener un control sobre un plan no implica rigidez si no que es la capacidad de revisar la ejecución de los objetivos con sus resultados para la revisión estratégica, la planeación requiere tiempo y recursos que pueden ser considerados innecesarios cuando no se tiene la visión correcta, ya que se puede prevenir incertidumbre y falta de dirección en una organización lo que implica tiempo y recursos superiores y no controlados, el tamaño de la empresa no determina la necesidad de un plan de marketing, lo que lo establece es la visión de la organización hacia los objetivos que pretende alcanzar a corto mediano y largo plazo.

\section{Referencias}

[1] Ancín, J. M. (2013). El plan de Marketing en la PYME. Madrid: ESIC. 